\title{
Fe-Co-Cr nanocomposites for application in self-regulated rf heating
}

\author{
K. J. Miller, ${ }^{1, a)}$ A. Colletti, ${ }^{1}$ P. J. Papi, ${ }^{1}$ and M. E. McHenry ${ }^{1,2}$ \\ ${ }^{1}$ Department of Materials Science and Engineering, Carnegie Mellon University, Pittsburgh, \\ Pennsylvania 15217, USA \\ ${ }^{2}$ Department of Physics, Carnegie Mellon University, Pittsburgh, Pennsylvania 15217, USA \\ (Presented 22 January 2010; received 3 November 2009; accepted 13 January 2010; \\ published online 19 April 2010) \\ $\mathrm{Fe}-\mathrm{Co}-\mathrm{Cr}$ alloys have been developed with a Curie temperature, $\mathrm{T}_{\mathrm{c}}$, appropriate for ferrofluid \\ cooling and self-regulated heating applications. These alloys have low Curie temperatures, moderate \\ magnetic moments and provide increased heat capacity in a liquid used in a thermal cycle. \\ Amorphous powders have been synthesized by cryo-SPEX milling melt-spun ribbons at $77 \mathrm{~K}$. \\ Transmission electron microscopy reveals cryomilled magnetic nanoparticles (MNPs) with a mean \\ diameter of $4.2 \mathrm{~nm}$ to form agglomerates $\sim 30 \mathrm{~nm}$ in size. Vibrating sample magnetometer and \\ superconducting quantum interference device magnetometry of amorphous powders reveal a \\ specific magnetization, $\sigma_{\mathrm{s}}$, of $104 \mathrm{emu} / \mathrm{g}$ at $4 \mathrm{~K}$ in a $300 \mathrm{mT}$ field and a $\mathrm{T}_{\mathrm{c}}$ of $335 \mathrm{~K}$. Nanoparticles \\ were suspended in ferrofluids by ultrasonication with a Pluronic F127 surfactant to stabilize them in \\ aqueous solution. Ferrofluids of varying MNP concentration were rf heated in a $27.2 \mathrm{mT}$ field at 267 \\ $\mathrm{kHz}$. For $1.24 \mathrm{vol} \%$ of MNPs in the ferrofluid, a solution reached temperatures $>50{ }^{\circ} \mathrm{C}$ in $\sim 70 \mathrm{~s}$, \\ and showed Curie-limiting temperature behavior at $\sim 75{ }^{\circ} \mathrm{C}$. These results demonstrate self-limited \\ heating of $\mathrm{FeCoCr}$ MNPs at $75{ }^{\circ} \mathrm{C}$ which may have application in polymer curing. () 2010 \\ American Institute of Physics. [doi:10.1063/1.3349043]
}

\section{INTRODUCTION}

Applications of thermodynamics to heat engines, refrigerators, heat pumps, etc., rely on the efficient use of thermodynamic cycles. Magnetic nanoparticles (MNPs) have been extensively studied for magnetocaloric effect (MCE) application. One of the foremost reasons for interest in MNPs for MCE applications is the ability to suspend them in fluids. Such ferrofluids can be moved and guided with an applied dc field, provide additional heat capacity to the liquid in the thermal cycle and offer advantages in heat conduction.

For naval applications in a self-pumping, ferrofluid cooled system, the $T_{c}$ of the MNPs should lie between ambient, ocean water temperature, and a desired characteristic device operating temperature $\left(70-300{ }^{\circ} \mathrm{C}\right) .{ }^{1}$ In such a selfpumping system, MNPs, suspended in a fluid, are attracted to a magnetic field gradient near the transducer heat load. At this thermal load, convection currents heat the particles above their $\mathrm{T}_{\mathrm{c}}$ where the material becomes paramagnetic. At the heat release station, permanent magnets create a strong magnetic field that aligns the particle magnetization with the field. Convective currents then remove heat from the particles and they return to the ferromagnetic state. A magnetocaloric cycle can be used for exploiting the ferromagnetic to paramagnetic phase transformation at the Curie temperature $\left(\mathrm{T}_{\mathrm{c}}\right)$ in suitable alloys in the $\mathrm{FeCoCr}$ system. Tuning the $\mathrm{T}_{\mathrm{c}}$ in MNPs is also critical to self-regulated radio frequency (rf) heating applications ${ }^{2}$ where heating diminishes near the $T_{c}$ of MNPs.

We report on new $\mathrm{Fe}-\mathrm{Co}-\mathrm{Cr}$ alloys developed to achieve lower $\mathrm{T}_{\mathrm{c}}$ appropriate for use in ferrofluid cooling applica-

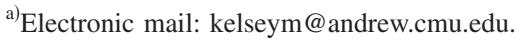

tions. These same type of ferrofluids with appropriate $T_{c}$ 's offer dual use application in the self-regulated heating of MNPs (Ref. 2) in temperature ranges of interest for applications of polymer curing ${ }^{3}$ and cancer thermotherapies. ${ }^{4}$ These alloys are interesting due to their low $\mathrm{T}_{\mathrm{c}}$, moderate magnetic moment, and increased heat capacity in a liquid used in a thermal cycle.

Prior work has shown that Co increases the Curie temperature and saturation magnetization of amorphous and nanocrystalline alloys, ${ }^{5}$ whereas $\mathrm{Cr}$ is observed to decrease both. ${ }^{6,7}$ Co (Ref. 8) and Cr also serve to passivate the MNP surfaces and prevent corrosion in aqueous solutions. Our research focuses on tuning Curie temperatures in magnetic nanostructures produced by changing the $\mathrm{Fe}-\mathrm{Co}-\mathrm{Cr}$ ratios in amorphous ribbon. We pursue the end goal of producing aqueous ferrofluids suitable for cooling applications near room temperature as well as rf heating applications.

\section{EXPERIMENTAL PROCEDURE}

$\mathrm{Fe}-\mathrm{Co}-\mathrm{Cr}$ alloy ingots are prepared by electric arc melting mixtures of $\mathrm{Fe}$ (99.98 mass\%), Co (99.998 mass\%), $\mathrm{Cr}$ (99.96 mass\%), Zr (99.98 mass\%), and B (99.5 mass\%) pieces in a high purity Ar atmosphere. A Centorr Vacuum Systems arc melter was used to prepare precursor charge ingots for synthesis of melt-spun amorphous ribbon. Singleroller melt-spinning was used to cast $\left(\mathrm{Fe}_{65} \mathrm{Co}_{35}\right)_{71} \mathrm{Cr}_{18} \mathrm{Zr}_{7} \mathrm{~B}_{4}$ amorphous ribbons at cooling at a rate of $10^{6}{ }^{\circ} \mathrm{C} / \mathrm{s}$.

Since the $\mathrm{Fe}-\mathrm{Co}-\mathrm{Cr}$ alloy has a much lower $\mathrm{T}_{\mathrm{c}}$ in the as-cast amorphous state than in the nanocrystalline state, ribbons were cooled in liquid nitrogen to make them more brittle and avoid crystallization during cryogenic milling for $8 \mathrm{~h}$. Transmission electron microscopy (TEM) was used to 


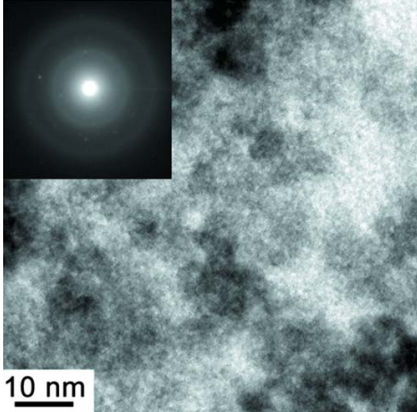

FIG. 1. (Color online) TEM image showing particle size and SAED showing absence of crystalline phases after cryomilling for $8 \mathrm{~h}$. (inset).

determine particle sizes and degree of crystallization after mechanical cryomilling. TEM was carried out on a JEOL 2000EX microscope with operating voltage of $200 \mathrm{keV}$. Selected area electron diffraction (SAED) was used to identify the presence of any crystalline phases. Both vibrating sample magnetometery (VSM) and a superconducting quantum interference device (SQUID) magnetometer were used to determine magnetic properties using various fields at room temperature and in fixed fields at 4-400 K, respectively. Nanoparticles of the desired $\mathrm{T}_{\mathrm{c}}$ were incorporated into aqueous ferrofluids by ultrasonication with a water soluble surfactant such as poly(ethylene glycol) or a block copolymer such as Pluronic F127.

rf ferrofluid heating was performed with a $2.0 \mathrm{~kW}$ Ameritherm Hotshot power supply with a variable frequency between $150-400 \mathrm{kHz}$ with maximum output of $400 \mathrm{~A}$ through a three-turn coil. A $27.2 \mathrm{mT}$ ac magnetic field at $267 \mathrm{kHz}$ was employed for our heating experiments. Temperature change was measured as a function of rf field exposure time using a Luxtron optical fiber temperature probe with an accuracy of $0.05^{\circ} \mathrm{C}$. Sample vials containing the ferrofluids were wrapped in Styrofoam insulation to avoid heat loss to the surroundings. Heating rates for concentrations of 1.24 and 1.21 vol \% ferrofluids with cryomilled $\left(\mathrm{Fe}_{65} \mathrm{Co}_{35}\right)_{71} \mathrm{Cr}_{18} \mathrm{Zr}_{7} \mathrm{~B}_{4}$ nanoparticles were measured.

\section{RESULTS AND DISCUSSION}

TEM particle size and size distribution measurements revealed cryomilled MNPs with a mean diameter of $4.2 \mathrm{~nm}$ to form agglomerates $\sim 30 \mathrm{~nm}$ in size (Fig. 1). The SAED pattern confirms the absence of crystalline phases after cryomilling for $8 \mathrm{~h}$ (Fig. 1 inset).

Magnetization vs. temperature curves in fields of 1-300 $\mathrm{mT}$ are shown in Fig. 2. The $\mathrm{T}_{\mathrm{c}}$ was determined by squaring the reduced magnetization and extrapolating to $\mathrm{m}=\mathrm{M} / \mathrm{Ms}$ $=0$ The $\left(\mathrm{Fe}_{65} \mathrm{Co}_{35}\right)_{71} \mathrm{Cr}_{18} \mathrm{Zr}_{7} \mathrm{~B}_{4}$ MNPs have a magnetic moment of $104 \mathrm{emu} / \mathrm{g}$ at $4 \mathrm{~K}$ and $300 \mathrm{mT}$ and a $\mathrm{T}_{\mathrm{c}}$ at $\sim 335 \mathrm{~K}$

For application in the self-pumping cooling system, the $\left(\mathrm{Fe}_{65} \mathrm{Co}_{35}\right)_{71} \mathrm{Cr}_{18} \mathrm{Zr}_{7} \mathrm{~B}_{4}$ nanoparticles were incorporated into aqueous solutions by ultrasonication with a Pluronic F127 surfactant. Concentrations of Pluronic F127 ranging at $0.150-0.175 M$ were used to obtain ferrofluids of varying viscosity and gelation temperatures. A $15 \%$ concentration of Pluronic F127 in water [Fig. 3(a)] is liquid at room temperature and stays liquid when heated to temperatures in excess

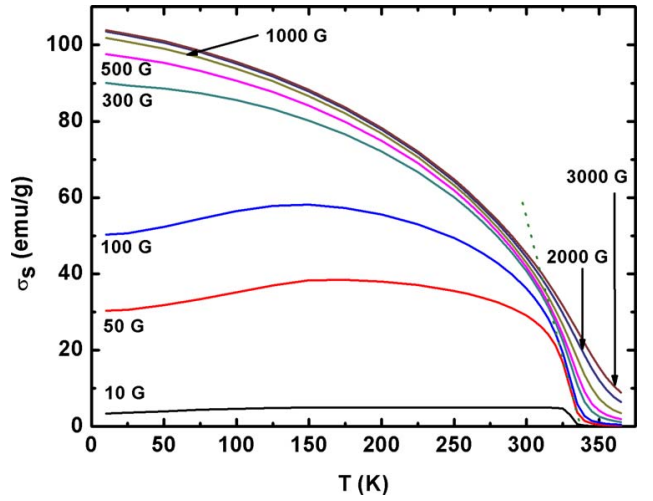

FIG. 2. (Color online) SQUID data showing specific magnetization vs temperature for the $\left(\mathrm{Fe}_{65} \mathrm{Co}_{35}\right)_{71} \mathrm{Cr}_{18} \mathrm{Zr}_{7} \mathrm{~B}_{4}$ alloy at various applied fields.

of $90^{\circ} \mathrm{C}$, while higher concentrations gelled even at room temperature [Fig. 3(c)]. Control of both viscosity and gelation temperature were key factors in this application. Ferrofluids remained stable for several weeks.

Ferrofluids of varying MNP concentration were rf heated by applying a $27.2 \mathrm{mT}$ ac magnetic field at $267 \mathrm{kHz}$. Temperature change was measured as a function of exposure time in the cryomilled $\mathrm{Fe}-\mathrm{Co}-\mathrm{Cr}$ ferrofluids using a Luxtron optical fiber temperature probe. Using a 1.24 vol \% concentration of $\left(\mathrm{Fe}_{65} \mathrm{Co}_{35}\right)_{71} \mathrm{Cr}_{18} \mathrm{Zr}_{7} \mathrm{~B}_{4}$ MNPs in $10 \mathrm{ml}$ of $0.150 \mathrm{M}$ Pluronic F127 ferrofluid, the solution was effectively heated to reach temperatures $>50{ }^{\circ} \mathrm{C}$ in $\sim 70$ s, while demonstrating Curie-limiting self-regulating behavior was demonstrated $\sim 74.5{ }^{\circ} \mathrm{C}$ (Fig. 4).

As seen from Fig. 4, the heating rate dies off quickly near $\mathrm{T}_{\mathrm{c}}$ (for a given field) since $\mathrm{dM} / \mathrm{dT}$ changes dramatically at this temperature. However, there is still a measurable heating rate above this temperature due to broad transition from ferromagnetic to paramagnetic. At $74.5^{\circ} \mathrm{C}$ the magnetic moment of the particles is near zero and the heating rate reaches equilibrium with the heat lost to the surroundings. This selfregulated heating effect is shown to be independent of applied field. It is also interesting to note a periodic fluctuation of $\sim 0.5{ }^{\circ} \mathrm{C}$ near this self-limiting temperature. This is attributed to the particles losing their magnetic moment above $74.5^{\circ} \mathrm{C}$, followed by heat being lost to the surroundings which brings the temperature back down to $\sim 74{ }^{\circ} \mathrm{C}$ where the particles become ferromagnetic and start heating again.

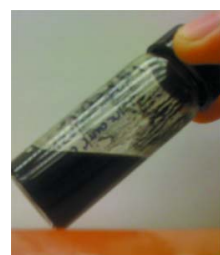

(a)

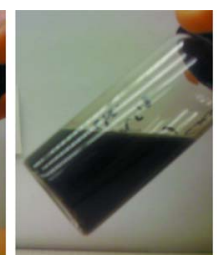

(b)

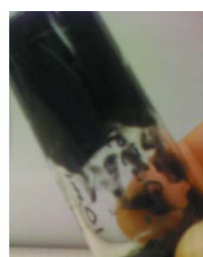

(c)
FIG. 3. (Color online) $\left(\mathrm{Fe}_{65} \mathrm{Co}_{35}\right)_{71} \mathrm{Cr}_{18} \mathrm{Zr}_{7} \mathrm{~B}_{4}$ MNPs incorporated into various concentrations of Pluronic F127 (a) 15\%, (b) 16\%, and (c) 17.5\% showing liquid in both $15 \%-16 \%$ concentrations and a gel formation in $17 \%$ concentration at room temperature. 


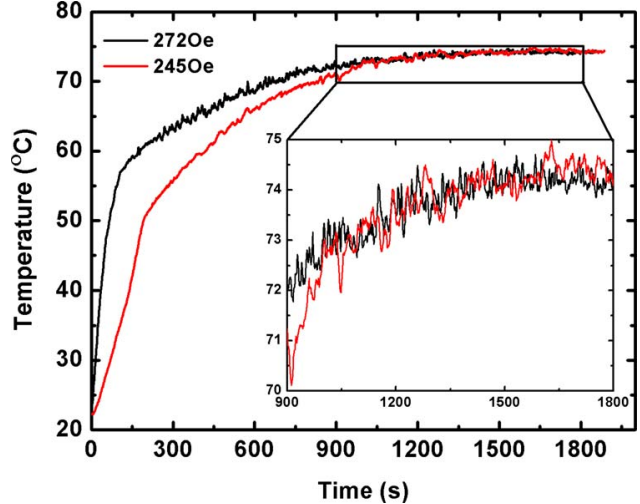

FIG. 4. (Color online) rf heating curves for $1.24 \mathrm{vol} \%$ concentration of $\left(\mathrm{Fe}_{65} \mathrm{Co}_{35}\right)_{71} \mathrm{Cr}_{18} \mathrm{Zr}_{7} \mathrm{~B}_{4}$ MNPs in $10 \mathrm{ml}$ of $0.150 M$ Pluronic F127 ferrofluid. rf coil operating at a frequency of $267 \mathrm{kHz}$ and given excitation fields.

\section{CONCLUSION}

We have synthesized amorphous $\mathrm{Fe}-\mathrm{Co}-\mathrm{Cr}$ nanoparticles which demonstrate a Curie-limited self-regulating effect at $\sim 74.5{ }^{\circ} \mathrm{C}$ which is independent of rf field amplitude. This ferrofluid has application in ferrofluid cooling devices where the ferromagnetic to paramagnetic transition temperature is at $70-300{ }^{\circ} \mathrm{C}$, as well as in self-regulated rf heating applications for curing of polymers. In the amorphous phase, the $T_{c}$ of the nanoparticles can be tailored by changing the concentration of $\mathrm{Co}$ and $\mathrm{Cr}$ for use in other applications such as hyperthermia and magnetic refrigeration near room temperature.

\section{ACKNOWLEDGMENTS}

KJM and MEM acknowledge support from STTR Proposal "Novel Management of Transducer Heat and Nonlinearity" Topic No. N08-T020, Contract No. N00014-08-M0313. KJM and MEM gratefully acknowledge Ferro Solutions, Inc. with helpful discussions from Prof. O'Handley, Dr. Jiankang Huang, Jesse Simon, and Yiming Liu.

${ }^{1}$ R. Kuldip, U.S. Patent No. 5,462,685 (31 October 1995).

${ }^{2}$ C. L. Ondeck, A. H. Habib, P. Ohodnicki, K. J. Miller, C. A. Sawyer, P. Chaudhary, and M. E. McHenry, J. Appl. Phys. 105, 07B324 (2009).

${ }^{3}$ K. J. Miller, K. N. Collier, H. B. Soll-Morris, R. Swaminathan, and M. E. McHenry, J. Appl. Phys. 105, 07E714 (2009).

${ }^{4}$ A. H. Habib, C. L. Ondeck, P. Chaudhary, M. R. Bockstaller, and M. E. McHenry, J. Appl. Phys. 103, 07A307 (2008).

${ }^{5}$ F. Johnson, A. Hsiao, C. Ashe, D. E. Laughlin, D. Lambeth, M. E. McHenry, and L. K. Varga, Proceedings of the first IEEE Conference on Nanotechnology, Maui, HI, 28-30 October 2001 (unpublished).

${ }^{6}$ V. Franco, C. F. Conde, A. Conde, and L. F. Kiss, J. Magn. Magn. Mater. 215-216, 400 (2000).

${ }^{7}$ F. Johnson and R. D. Shull, J. Appl. Phys. 99, 08 K909 (2006).

${ }^{8}$ Z. Turgut, N. T. Nuhfer, H. R. Piehler, and M. E. McHenry, J. Appl. Phys. 85, 4406 (1999). 